\title{
Compostagem e fermentação de resíduos de pescado para produção de fertilizantes orgânicos
}

\author{
Waste composting and proving fish for production the organic \\ fertilizers
}

\author{
Fernanda San Martins Sanes ${ }^{*}$; André Samuel Strassburger ${ }^{2}$; \\ Fábio Batista Araújo ${ }^{3}$; Carlos Alberto Barbosa Medeiros ${ }^{4}$
}

\section{Resumo}

Os volumes de resíduos gerados na atividade pesqueira são cada vez maiores em virtude do aumento da demanda por esses produtos. Isto implica na necessidade de medidas rápidas de transformação e ciclagens desses materiais. Dessa forma, objetivou-se avaliar o uso dos resíduos gerados na atividade pesqueira como fonte de adubos orgânicos em sistemas de produção agrícola familiar de base ecológica. O experimento foi realizado, na Estação Experimental Cascata/Embrapa Clima Temperado, foi avaliado todo processo de compostagem e o de fermentação dos resíduos de peixe, identificando os principais pontos que viabilizam o uso desses adubos em sistemas de produção de base ecológica. O processo de compostagem da casca de arroz revelou-se incompleto durante o período de realização do experimento. O composto elaborado com resíduos de pescado e casca esgotada de acácia apresenta-se como uma boa fonte de nutrientes para as culturas, podendo ser indicado como adubo orgânico para sistemas de produção de base ecológica. Em relação ao fertilizante orgânico líquido, nas condições em que o experimento foi realizado, conclui-se que o composto resultante da fermentação aeróbica ou anaeróbica do resíduo de pescado, apresenta-se como uma viável fonte de nutrientes para sistemas produtivos de base ecológica. Entretanto, estudos complementares necessitam ser conduzidos, para melhor entendimento e qualificação de ambos os processos.

Palavras-chave: Reutilização, reciclagem, agroecologia

\begin{abstract}
The volumes of waste generated in the fishing activity are increasing due to the increase in demand for these products. This implies the need for fast processing and cycling of these materials. Thus, the aim of this study was to evaluate the use of waste generated in the fishing activity as a source of organic fertilizers in agricultural production systems familiar ecological basis. The experiment was conducted at the Experimental Station Cascade / Embrapa Temperate Climate was assessed throughout the composting process and the fermentation of fish waste, identifying the main points that enable the use of these fertilizers in farming systems ecological base. The composting process of rice husk revealed be incomplete during the experiment. The compound prepared with fish waste and exhausted bark of acacia presents itself as a good source of nutrients for crops, which may be suitable as organic fertilizer for production of ecologically-based systems. For liquid organic fertilizer, the conditions under which the experiment was conducted, it is concluded that the compound resulting from aerobic or anaerobic fermentation of fish waste, present themselves as a viable source of nutrients for productive systems of ecological base. However, further studies need to be conducted to better understanding and qualification of both processes.
\end{abstract}

Key words: Reuse, recycling, agroecology

' Discente, Universidade Federal de Santa Maria, UFSM, Santa Maria, RS. E-mail: fernandasanes@gmail.com

2 Pesquisador, FEPAGRO, Serra do Nordeste, Fazenda Souza, Caxias do Sul, RS. E-mail: strassburger.as@gmail.com

3 Discente, Universidade Federal de Pelotas, UFPel, Capão do Leão, RS. E-mail: fabarujo@gmail.com

${ }^{4}$ Pesquisador, EMBRAPA Clima Temperado, Distrito Monte Bonito, Pelotas, RS. E-mail: carlos.medeiros@embrapa.br Autor para correspondência 


\section{Introdução}

Nos sistemas de produção de base ecológica, um dos fatores limitantes enfrentados pelos agricultores é a disponibilidade de fertilizantes que se enquadrem nas especificidades deste tipo de produção. Neste contexto, a reciclagem de resíduos oriundos das mais diversas cadeias produtivas, cujos descartes indevidos causam impactos negativos ao ambiente, apresenta-se como uma importante alternativa para a produção de fertilizantes orgânicos.

A ausência de tecnologias que possibilitem o processamento destes resíduos para a fabricação de fertilizantes, como é o caso dos resíduos provenientes da atividade pesqueira, pode ter como conseqüência o impacto ambiental causado pelo descarte indevido desse material, poluindo os recursos hídricos, o solo e o ar.

Neste sentido, embora ainda incipiente algumas técnicas vem sendo testadas em relação ao processamento do resíduo de pescado, através da compostagem e da fermentação, apresentandose como alternativas viáveis para a produção de fertilizantes, em virtude de sua elevada qualidade nutricional e biológica (ROSA, 2009).

O processo de compostagem é uma das formas mais empregada para o aproveitamento de resíduos, para atividades agrícolas, no entanto, existe outra forma de utilização destes resíduos, que é a fermentação do material. O processo fermentativo de resíduos, como os de pescado, com a finalidade de estabilização do material, recebe o nome de ensilagem, e tem como produto final o líquido chamado de silagem (TATTERSON; WINDSOR, 1974).

O processo para preparação da silagem consiste basicamente em acidificar o $\mathrm{pH}$ da massa triturada, deixando livre a ação das enzimas próprias dos tecidos, que terminam liquefazendo o produto. A silagem é normalmente acidificada a um $\mathrm{pH}$ entre 3,9 e 4,2 , a uma temperatura ambiente de $27^{\circ} \mathrm{C}$ a $30^{\circ} \mathrm{C}$ (VIDOTTI; GONÇALVES, 2006).
Duas metodologias básicas podem ser utilizadas na obtenção de uma silagem de resíduo de peixes; por adição de ácidos minerais ou orgânicos, tais como os ácidos fórmico, sulfúrico, clorídrico, propiônico, acético, fosfórico, dentre outros, ou empregando microrganismos produtores de ácido lático juntamente com uma fonte de carboidratos (VIDOTTI; GONÇALVES, 2006). Em um processo fermentativo utilizando este tipo de resíduo, o cuidado com o $\mathrm{pH}$, mantendo-o baixo, se torna imprescindível, eliminando assim qualquer condição para o desenvolvimento de microorganismos indesejáveis e prejudiciais ao processo (OETTERER, 2002).

A compostagem e fermentação são processos relativamente simples, no entanto necessitam de cuidados e atenção na sua condução. Os dois processos são práticos, econômicos e acessíveis apresentando-se como alternativa viável para a produção de adubos orgânicos. Não exigem equipamentos ou procedimentos de custo elevado ou mão de obra especializada, além dos produtos finais apresentarem elevada qualidade nutricional e biológica (ARRUDA; BORGHESI; OETTERER, 2007). A elevação dos teores de matéria orgânica, fósforo, potássio, cálcio e magnésio, o aumento pH e da saturação por bases e da capacidade de troca catiônica, pela adição dos adubos orgânicos, permitem melhorar a fertilidade dos solos nos sistemas de produção orgânicos (OLIVEIRA; LIMA; CAJAZEIRA, 2004).

Objetivou-se avaliar a produção de compostos orgânicos e fertilizantes orgânicos líquidos a base de resíduos de pescado, respectivamente, através do processo de compostagem e fermentação.

\section{Material e Métodos}

Durante os anos de 2010 e 2011, foram realizados dois experimentos na central de resíduos da Estação Experimental Cascata (EEC) - Embrapa Clima Temperado (CPACT). A Estação está localizada nas coordenadas $31^{\circ} 37^{\prime} \mathrm{S}$ e $052^{\circ} 31^{\prime} \mathrm{W}$, situada 
no distrito de Cascata, $5^{\circ}$ distrito de Pelotas. De acordo com Rambo (1994), está inserida na porção fisiográfica denominada Serra do Sudeste ou Serra dos Tapes, tendo altitudes entre 200 e $500 \mathrm{~m}$.

Os resíduos de pescado utilizados foram obtidos na indústria de processamento Torquato Pontes Pescados S/A, localizada no município de Rio Grande/RS (3201'40” S 52 05'40"'W) e na Colônia de Pescadores - Z3, localizada nas coordenadas 3142’06. 5"S 52॰09'25. 0"W, $2^{\circ}$ distrito do município de Pelotas/ RS. Para a compostagem dos resíduos, utilizaram-se duas fontes adicionais de carbono, casca de arroz in natura e casca esgotada de acácia, a qual recebe esta denominação após passar pelo processo de extração de tanino, com água e altas temperaturas e pressão.
Esses materiais foram usados separadamente, resultando em dois compostos distintos. A casca de arroz foi obtida junto à indústria de beneficiamento de arroz, localizada no município de Pelotas - RS e a casca de acácia na indústria TANAC de produção de tanino no município de Montenegro - RS.

Antes de serem submetidas aos processos de compostagem e fermentação, foram coletadas amostras representativas das diferentes matériasprimas e analisadas quimicamente (Tabela 1). As amostras da primeira compostagem foram encaminhadas para o laboratório do Departamento de Solos da Universidade Federal de Pelotas e as amostras da segunda compostagem para a Universidade Federal do Rio Grande do Sul no município de Porto Alegre.

Tabela 1. Composição inicial das matérias- primas utilizadas nas diferentes épocas de compostagens. Embrapa Clima Temperado, Estação Experimental Cascata, 2010 e 2011.

\begin{tabular}{|c|c|c|c|c|c|}
\hline \multirow{2}{*}{ Nutrientes } & \multirow{2}{*}{$\begin{array}{c}\text { Resíduo de } \\
\text { pescado. }\end{array}$} & \multicolumn{2}{|c|}{$1^{\mathrm{a}}$ compostagem } & \multicolumn{2}{|c|}{$2^{\mathrm{a}}$ compostagem } \\
\hline & & Casca de acácia & Casca de arroz & Casca de acácia & Casca de arroz \\
\hline pH & 6,1 & 6,2 & 7,2 & 6,3 & 7,2 \\
\hline $\mathrm{C} / \mathrm{N}$ & $3: 1$ & $34: 1$ & $130: 1$ & $30: 1$ & $128: 1$ \\
\hline $\mathrm{C}\left(\mathrm{gkg}^{-1}\right)$ & 240,90 & 499,70 & 436,00 & 460,00 & 410,00 \\
\hline$N\left(\mathrm{~g} \mathrm{~kg}^{-1}\right)$ & 81,48 & 14,75 & 3,35 & 15,00 & 3,20 \\
\hline$P\left(\mathrm{~g} \mathrm{~kg}^{-1}\right)$ & 7,29 & 0,21 & 0,42 & 0,20 & 0,60 \\
\hline K $\left(\mathrm{g} \mathrm{kg}^{-1}\right)$ & 6,50 & 4,60 & 0,30 & 0,40 & 0,28 \\
\hline $\mathrm{Ca}\left(\mathrm{g} \mathrm{kg}^{-1}\right)$ & 100,92 & 15,04 & 0,72 & 19,00 & 0,22 \\
\hline $\operatorname{Mg}\left(\mathrm{g} \mathrm{kg}^{-1}\right)$ & 1,87 & 1,29 & $<0,01$ & 0,50 & 0,70 \\
\hline $\mathrm{Cu}\left(\mathrm{mg} \mathrm{kg}{ }^{-1}\right)$ & 4,20 & 3,75 & 1,41 & 4,00 & 4,00 \\
\hline Zn (mg kg-1) & 74,22 & 9,15 & 17,12 & $<2,00$ & 20,00 \\
\hline $\mathrm{Fe}\left(\mathrm{mg} \mathrm{kg}^{-1}\right)$ & 143,22 & 244,80 & 281,80 & 256,00 & 559,00 \\
\hline $\operatorname{Mn}\left(\mathrm{mg} \mathrm{kg} \mathrm{g}^{-1}\right)$ & 34,81 & 0,90 & 305,00 & 28,00 & 295,00 \\
\hline
\end{tabular}

Fonte: Elaboração dos autores.

\section{Composto orgânico}

O processo de compostagem foi realizado em duas épocas, com inicio em Junho de 2010, e Maio de 2011, utilizando, para ambas as épocas, a metodologia descrita por Carney, Breitenbeck e Schellinger (2000). A análise química das matérias primas (TEDESCO et al., 1995) foi utilizada para se estabelecer as proporções adequadas de cada material de forma a obter-se a relação $\mathrm{C} / \mathrm{N}$ preconizada na literatura, em média 25:1.

A compostagem foi realizada em células de alvenaria com capacidade em torno de $3 \mathrm{~m}^{3}(1,45 \mathrm{~L}$ x 1,85 C x 1,1 H). Cada célula foi preenchida com uma camada de aproximadamente $30 \mathrm{~cm}$ da fonte de carbono, seguida por uma camada mais fina do resíduo de pescado, cerca de $20 \mathrm{~cm}$, como forma de 
evitar a compactação do material, o que acarretaria no desenvolvimento de condições anaeróbias, fato indesejado em um sistema de compostagem.

Foram trabalhados dois compostos distintos:

Composto 1 (C1) - mistura de resíduo de pescado e casca de arroz in natura. Com base nas análises dos resíduos, utilizou-se na compostagem a proporção de três quilos de resíduo de peixe para um quilo de casca de arroz. (3:1), totalizando para cada $\mathrm{m}^{3}$ da mistura, $244 \mathrm{~kg}$ de resíduo de pescado e 81,3 $\mathrm{kg}$ de casca de arroz. Essa proporção foi obedecida nas duas épocas de instalação dos experimentos.

Composto 2 (C2) - mistura de resíduo de pescado e casca esgotada de acácia. A proporção dos materiais utilizados na compostagem foi de dois quilos de resíduo de peixe para um quilo de casca esgotada de acácia (2:1), no primeiro experimento, e de um quilo de resíduo de peixe para cada quilo de casca esgotada de acácia (1:1) no segundo experimento. A diferença nas proporções se deve ao fato de que durante a armazenagem da casca de acácia, houve um inicio de compostagem, provocando uma diminuição da relação $\mathrm{C} / \mathrm{N}$ inicial. $\mathrm{Na}$ primeira compostagem, para cada $\mathrm{m}^{3}$ da mistura, utilizou-se $402 \mathrm{~kg}$ de resíduo de pescado e $201 \mathrm{~kg}$ de casca de acácia e na segunda, foram utilizadas $400 \mathrm{~kg}$ de resíduo de pescado e $400 \mathrm{~kg}$ de casca esgotada de acácia.

\section{Condução do processo de compostagem}

$\mathrm{O}$ teor de água das misturas em compostagem foi mantido em torno de $60 \%$, com avaliações semanais da umidade gravimétrica, adicionandose água quando necessário. Para a análise do teor de água foram retiradas, em cada baia, duas amostras do centro da pilha de compostagem. As amostras foram mantidas em estufa a $65^{\circ} \mathrm{C}$ até atingirem peso constante, normalmente, dentro de aproximadamente 48 horas, o cálculo foi realizado conforme EMBRAPA (1997): Umidade Gravimétrica $=100(\mathrm{a}-\mathrm{b}) / \mathrm{b}$, onde $\mathrm{a}=$ peso da amostra úmida (g) e b = peso da amostra seca $(\mathrm{g})$.

A temperatura foi monitorada diariamente durante o processo, utilizando-se termômetro digital, modelo TM1210H, colocado no centro da pilha a uma profundidade de aproximadamente 50 $\mathrm{cm}$. Por falta dos termômetros, as leituras iniciaram no sétimo dia após a instalação do experimento, não permitindo o registro das temperaturas nos primeiros dias de compostagem. A pilha era revolvida quando os valores de temperatura atingiam $70^{\circ} \mathrm{C}$.

No primeiro experimento foram realizados quatro revolvimentos no composto com resíduo de peixe mais casca de arroz $(13,33,55$ e 76 dias após o inicio do processo), e seis para o composto com casca de acácia $(13,33,55,76,87$ e 114 dias após o início do processo de compostagem). No segundo experimento, foram feitos quatro revolvimentos (21, 42, 70 e 105 dias após o inicio do processo), para ambos os compostos.

Para o controle do mau cheiro, na disposição das camadas dos diferentes materiais, a última foi de fonte de carbono, impossibilitando que o odor do inicio da compostagem atraísse animais indesejados, como moscas. Após o primeiro revolvimento, com a mistura das camadas, foram colocadas telas sobre as baias, impedindo a postura de ovos de insetos e o consumo do material compostado por pássaros.

$\mathrm{O}$ processo foi considerado completo e estabilizado, quando não se observaram oscilações significativas na temperatura, mesmo com o revolvimento da pilha e/ou adição de água. Após, foi feita a avaliação química dos diferentes compostos orgânicos, obtidos nas diferentes épocas.

\section{Fertilizante orgânico líquido}

Para a elaboração do fertilizante orgânico líquido, os resíduos foram triturados, pesados e colocados em bambonas plásticas com capacidade de 30L durante, aproximadamente, 60 dias.

Foi adicionado à massa, açúcar mascavo na proporção aproximada de $10 \%$ do volume e $0,25 \%$ 
do volume de ácido acético, conforme metodologia adaptada de Uchida et al. (2007). A adaptação constituiu-se na substituição do ácido sórbico, pelo ácido acético, o qual atende a Instrução Normativa $\mathrm{N}^{\circ} 64$ do Ministério da Agricultura, Pecuária e Abastecimento (MAPA, 2008), pois tem sua utilização permitida nos insumos destinados a sistemas orgânicos de produção.

Os dois ácidos possuem a mesma constante de acidez (pKa) ou constante de dissociação, possibilitando a substituição sem comprometer o processo de fermentação. $\mathrm{O}$ ácido reduz $\mathrm{o}$ $\mathrm{pH}$ durante o processo fermentativo inibindo o crescimento de bactérias que impedem a atuação das enzimas proteolíticas dos tecidos e da pepsina, dissolvendo as proteínas e liquefazendo o material em aproximadamente uma a duas semanas (OETTERER, 2006).

O açúcar mascavo foi utilizado como catalisador, aumentando a velocidade do processo de fermentação. Esse produto alimenta as bactérias responsáveis pela decomposição da matéria orgânica, benéficas ao processo fermentativo, dinamizando sua degradação. Foram testada diferentes concentrações de resíduo de pescado, 66,33 e $16 \%$ em dois processos fermentativos, anaeróbico e aeróbico.

Para cada bambona com $66 \%$ de resíduo de pescado, foram utilizados: 20 litros de resíduo de pescado e 10 litros de água. Nos tratamentos com $33 \%$ de resíduo de pescado, foram utilizados: 10 litros de resíduo de pescado e 20 litros de água, e para $16 \%$ de resíduo de pescado, foram utilizados: 5 litros de resíduo de pescado e 25 litros de água. Às três diferentes concentrações, foram adicionados 0,05 litros de ácido acético e $3 \mathrm{~kg}$ de açúcar mascavo.

No processo aeróbico, a massa foi agitada duas vezes ao dia (de manhã e à tarde) buscando-se a uniformidade do material. No processo anaeróbico, as bambonas foram lacradas, acoplando-se uma mangueira na tampa para a eliminação dos gases liberados durante o processo fermentativo. A extremidade externa da mangueira foi mergulhada em água para impedir a entrada de ar no processo, diminuindo também emissão de gases com odor indesejado, como o metano.

A massa foi misturada, retirando-se uma amostra do material, o qual foi coado, eliminando qualquer resíduo de pescado existente, resultando um produto homogêneo e líquido. Desta, amostras de $200 \mathrm{~mL}$ foram acondicionados em frascos âmbar, e encaminhadas para o laboratório de solos da Universidade Federal de Santa Maria, onde foi realizada a caracterização dos fertilizantes orgânicos líquidos, quanto aos teores de macro e micronutrientes.

As amostras referentes aos tratamentos com 66\% de resíduo de pescado não foram encaminhados, pois se verificou que o processo não foi eficiente, causando o apodrecimento do material no sistema aeróbico, e a falta de degradação no sistema anaeróbico.

\section{Resultados e Discussão}

\section{Compostagem}

Embora a realização dos experimentos em duas épocas não tenha sido com o objetivo de avaliar o efeito ambiente, verificou-se pouca variação no ambiente onde foram conduzidos os processos, não alterando os resultados finais obtidos nos diferentes processos.

Observaram-se, em ambas as épocas, comportamentos distintos dos dois materiais em relação às variações de temperatura durante $\mathrm{o}$ processo de compostagem (Figura 1). O composto a base de resíduo de peixe e casca de arroz apresentou oscilação mais acentuada se comparada a do composto à base de resíduo de peixe e casca esgotada de acácia. No composto 1 (resíduo de peixe + casca de arroz), houve uma queda quase constante da temperatura, caracterizando um processo inadequado de compostagem, o que não aconteceu com o composto 2 (resíduo de peixe + casca esgotada 
de acácia), onde pode-se observar oscilações que indicam que o processo foi completado de forma satisfatória. Para o processo cumprir todas suas etapas efetivamente, fase mesofílica deverá ter uma duração de aproximadamente cinco dias, e a termofílica, em média, trinta dias, a fim de eliminar qualquer organismo indesejado do processo de compostagem (KIEHL, 1998).

A variação de temperatura observada em C2 é característica dos processos de compostagem, com valores semelhantes ao estudo de Richard (1995), sobre compostagem de diferentes resíduos orgânicos. Para o composto orgânico $\mathrm{C} 1$, as temperaturas obtidas estão aquém daquelas normalmente observadas nos processos de compostagem. Esse resultado pode ser explicado pelo fato da casca de arroz apresentar uma estrutura química não favorável à decomposição, com elevados teores de sílica, material de difícil processamento pelos microrganismos.

Esta dificuldade no processo de compostagem refletiu-se no comportamento da temperatura durante a compostagem, com um aumento muito rápido nos primeiros dias, ultrapassando os $70^{\circ} \mathrm{C}$, mas com um declínio quase contínuo no decorrer do processo. O composto com casca de acácia atingiu as temperaturas adequadas ao processo de compostagem na primeira semana, permanecendo nesse patamar pelo período necessário para tornar a fase termofílica eficiente. Fernandes e Soares Junior (1992), avaliando o comportamento térmico de leiras de compostagem de resíduos gerados pela agroindústria, observaram um comportamento semelhante ao composto à base de pescado e casca esgotada de acácia, onde o período termófilo permaneceu por um período de aproximadamente três meses, conferindo um material final adequado para o uso como fertilizante orgânico.
O composto 1 em ambas as épocas, aproximadamente 20 dias após o inicio da compostagem, registrou temperaturas inferiores ao limite superior da fase mesofílica que é de $45^{\circ} \mathrm{C}$, indicando que o processo de compostagem estaria entrando na fase de maturação. Decorridos cerca de 60 dias de compostagem, o material registrou temperatura semelhante ao ambiente caracterizando o final do processo.

$\mathrm{O}$ composto $\mathrm{C} 2$ retomou a fase mesofílica cerca de 100 dias após o início do processo, com registros de temperaturas em torno de $45^{\circ} \mathrm{C}$, valores estes que diminuíram gradativamente, indicando que o material estaria entrando na última fase do processo de compostagem. Aos 140 dias após o inicio da compostagem o composto entrou na fase de maturação, atingindo a temperatura ambiente após 150 dias de seu início, quando foi considerado finalizado.

A redução de volume em cada composto orgânico, nas duas épocas de compostagem, foi de aproximadamente $25 \%$ para o composto a base de resíduo de pescado e casca de arroz, e de 50\% para o composto a base de resíduo de pescado e casca esgotada de acácia. A menor redução no composto 1 se deu devido à ineficiência do processo de compostagem, que pode ser evidenciado pela presença de casca de arroz ainda inteira no produto final.

O composto elaborado a base de resíduo de pescado e casca esgotada da acácia $(\mathrm{C} 2)$, tendeu a apresentar os maiores valores de macronutrientes, especialmente na segunda compostagem (Tabela 2). As maiores diferenças foram observadas para o nitrogênio e o cálcio. Essa tendência não foi tão clara para os micronutrientes analisados, onde o Mn apresentou as maiores concentrações no composto elaborado a partir de resíduo de pescado e casca de arroz (Tabela 2). 
Figura 1. Oscilações de temperatura durante o processo de compostagem, nas diferentes fases, de dois compostos: a) C1 - resíduo de peixe + casca de arroz, em duas épocas distintas; b) C2 - resíduo de peixe + casca de acácia, em duas épocas distintas. As setas indicam os revolvimentos realizados durante o processo. Estação Experimental Cascata, Embrapa Clima Temperado, Pelotas, RS (2010, 2011).

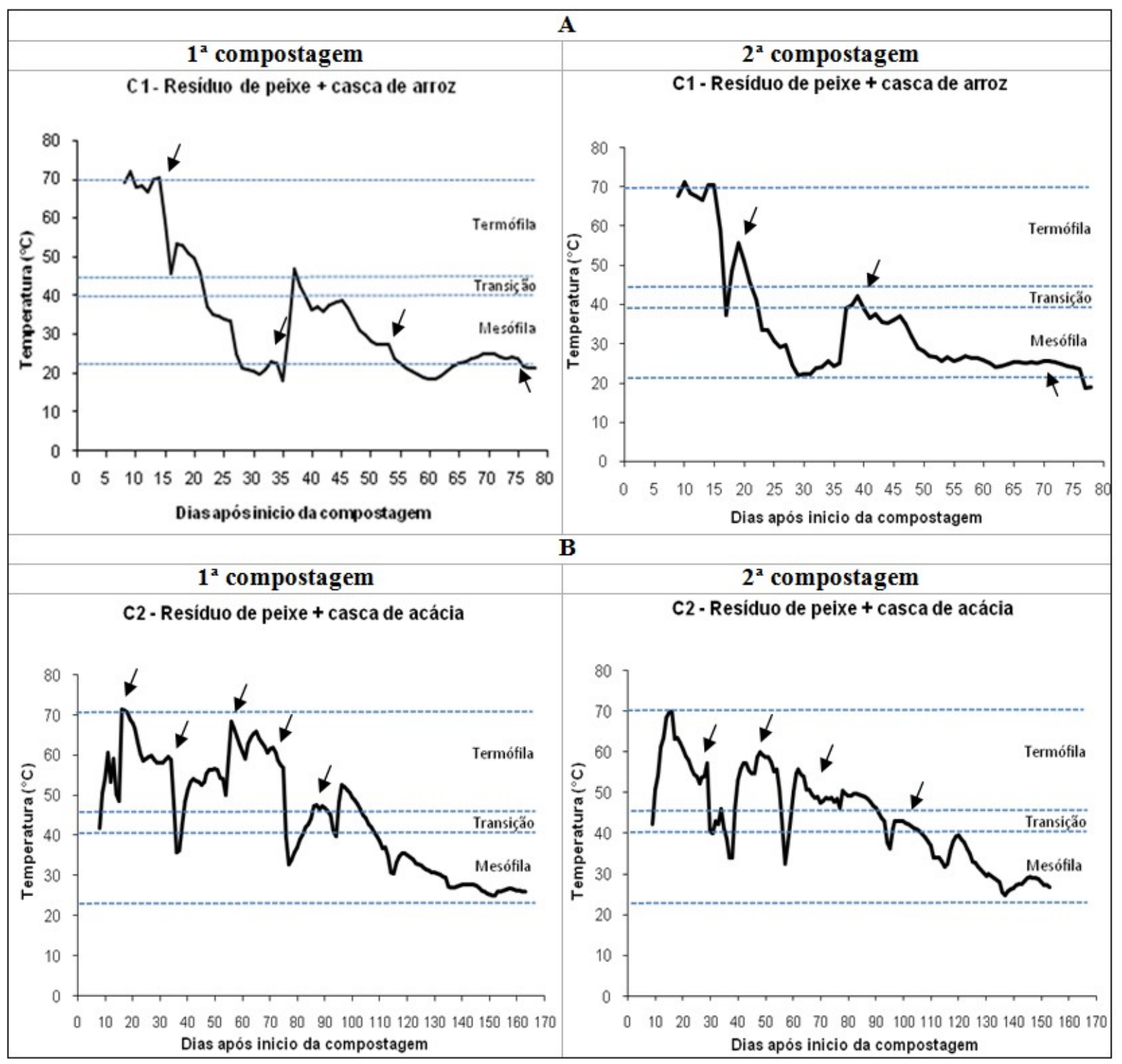

Fonte: Elaboração dos autores. 
Tabela 2. Concentração de Ca; P; N; K; Mg; S e Na (\%); Cu; Zn; Fe; Mn e B (mg. kg-1) em compostos elaborados a partir de resíduos de pescado + casca de arroz e resíduo de pescado + casca esgotada de acácia. Estação Experimental Cascata, Embrapa Clima Temperado, Pelotas, RS. (2010 2011).

\begin{tabular}{|c|c|c|c|c|}
\hline \multirow{2}{*}{ Nutrientes } & \multicolumn{2}{|c|}{ Peixe + casca de arroz } & \multicolumn{2}{|c|}{ Peixe + casca de acácia } \\
\hline & $1^{\mathrm{a}}$ compostagem & $2^{\mathrm{a}}$ compostagem & $1^{\text {a }}$ compostagem & $2^{\mathrm{a}}$ compostagem \\
\hline C. org & 32,0 & 39,0 & 37,0 & 41,0 \\
\hline Nitrogênio & 1,3 & 0,9 & 3,9 & 4,0 \\
\hline Fósforo & 4,0 & 1,4 & 4,2 & 2,9 \\
\hline Potássio & 0,21 & 0,26 & 0,26 & 0,25 \\
\hline Cálcio & 7,4 & 2,9 & 10,0 & 6,8 \\
\hline Magnésio & 0,20 & 0,10 & 0,23 & 0,20 \\
\hline Enxofre & 0,21 & 0,15 & 0,39 & 0,43 \\
\hline Cobre & 3,0 & 2,0 & 6,0 & 6,0 \\
\hline Zinco & 94,0 & 21,0 & 96,0 & 71,0 \\
\hline Ferro & 372,0 & 334,0 & 653,0 & 497,0 \\
\hline Manganês & 279,0 & 175,0 & 55,0 & 44,0 \\
\hline Boro & 3,0 & 7,0 & 7,0 & 25,0 \\
\hline
\end{tabular}

Fonte: Elaboração dos autores.

O composto elaborado a partir de resíduos de pescado mais casca de arroz, na primeira compostagem, apresentou concentração de $\mathrm{N}$ de $1,3 \%$, sendo inferior, numericamente, ao composto feito a partir de composto de peixe mais casca esgotada de acácia que foi de 3,9\%. Resultado semelhante foi encontrado na segunda compostagem, onde o composto a base de resíduo de pescado e casca de arroz apresentou teores de nitrogênio igual a $0,92 \%$ enquanto o composto a base de resíduo de pescado e casca esgotada de acácia apresentou 4,0\% de nitrogênio.

Os resultados são conseqüência, possivelmente, da composição inicial das matérias-primas, onde os teores de nitrogênio das duas fontes de carbono utilizadas são diferentes. A concentração inicial de nitrogênio da casca esgotada de acácia foi cinco vezes maior se comparada com a casca de arroz, o que se refletiu na composição final do material compostado. Em função do elevado teor de $\mathrm{N}$ no resíduo de pescado, e do maior volume deste resíduo utilizado no composto com casca de arroz, em comparação àquele com casca esgotada de acácia, esperava-se que o composto com casca de arroz apresentasse maiores teores de $\mathrm{N}$, resultado que não se verificou. A ineficiência do processo de compostagem da casca de arroz, possivelmente tenha sido responsável pelo baixo teor de $\mathrm{N}$ no composto final, em função das perdas por volatilização. Neste composto observou-se, durante os revolvimentos, forte cheiro de amônia, evidenciando a volatilização do $\mathrm{N}$, fato que não foi constatado no processo de compostagem do resíduo com casca esgotada de acácia.

Para o cálcio, observa-se a mesma tendência do Nitrogênio, onde o composto 2 apresentou valores superiores ao composto 1 , sendo aproximadamente $35 \%$ e $134 \%$ maior na primeira e segunda compostagem, respectivamente. Os maiores teores de cálcio no composto 2 , devem-se, possivelmente, a diferente composição das fontes de carbono utilizadas. Os maiores teores iniciais de cálcio da casca esgotada de acácia se refletiram nos maiores valores desse nutriente no composto 2, muito embora o volume inicial de resíduo de pescado misturado à casca de arroz, composto 1 , tenha sido superior, o que levaria a expectativa de maior teor de cálcio na composição final deste composto.

Os teores de fósforo das matérias-primas foram muito semelhantes, o que, provavelmente, 
determinou valores equivalentes para esse nutriente nos dois compostos. O potássio, magnésio e enxofre, não apresentaram dados numéricos diferentes entre os compostos nas diferentes compostagens, embora se tenha adicionados mais resíduo de pescado no composto com casca de arroz.

Em relação aos micronutrientes, o ferro foi o elemento que se apresentou em maior quantidade em ambos os compostos, nas diferentes épocas. Estes valores são explicados pela composição química das matérias-primas. O resíduo de pescado, tinha na sua composição inicial, $143,67 \mathrm{mg} \mathrm{kg}^{-1}$ de ferro, que adicionado a 244,78 $\mathrm{mg} \mathrm{kg}^{-1}$ e $281,86 \mathrm{mg}$ $\mathrm{kg}^{-1}$ das cascas de arroz e acácia, respectivamente, explicam os dados obtidos.

Da mesma forma, os teores de manganês, são explicados pela composição inicial dos materiais, onde os índices na casca de arroz foram superiores em comparação a casca esgotada de acácia. Para o cobre, boro e zinco não foram observadas tendências claras em relação às concentrações finais nos diferentes compostos, nas duas compostagens realizadas.

\section{Fertilizante orgânico líquido}

Observou-se no sistema aeróbico uma tendência de menor concentração de nitrogênio no fertilizante fabricado a partir de uma concentração de 16\% de resíduo de pescado, comparado a concentração de 33\% (Tabela 3) o que, possivelmente, pode ser explicado pelo efeito de diluição. Os demais nutrientes apresentaram valores menores se comparados com a composição inicial do produto, o que pode ser explicado, pelo menos parcialmente, pelo efeito de diluição.

O tratamento anaeróbico apresentou, de maneira geral, valores numericamente superiores ao aeróbico, embora a grande variabilidade observada nos dados obtidos, evidenciando a falta de consistência dos resultados.

Um fator que beneficia o fertilizante em sistema anaeróbico, em relação ao aeróbico, é o fato de ser um processo que não requer muita mão de obra, uma vez que todo o processo acontece sem revolvimento da massa.

Tabela 3. Teores de nutrientes de fertilizantes orgânicos líquidos fabricados a base de resíduos de pescado, em diferentes concentrações (16\% e 33\%), em sistema aeróbico e anaeróbico. Embrapa Clima Temperado, Estação Experimental Cascata, Pelotas, RS (2011).

\begin{tabular}{|c|c|c|c|c|}
\hline \multirow{2}{*}{ Variáveis* } & \multicolumn{2}{|c|}{ Aeróbico } & \multicolumn{2}{|c|}{ Anaeróbico } \\
\hline & $16 \%$ & $33 \%$ & $16 \%$ & $33 \%$ \\
\hline $\mathrm{N}$ total $\left(\mathrm{g} \mathrm{L}^{-1}\right)$ & 4,36 & 14,65 & 14,07 & 15,56 \\
\hline$P\left(g^{-1}\right)$ & 2,02 & 3,87 & 2,34 & 2,45 \\
\hline $\mathrm{K}\left(\mathrm{g} \mathrm{L}^{-1}\right)$ & 0,88 & 0,59 & 1,64 & 1,24 \\
\hline $\mathrm{Na}\left(\mathrm{g} \mathrm{L}^{-1}\right)$ & 0,56 & 0,40 & 1,28 & 0,72 \\
\hline $\mathrm{Ca}\left(\mathrm{g} \mathrm{L}^{-1}\right)$ & 2,49 & 1,63 & 3,49 & 5,03 \\
\hline $\operatorname{Mg}\left(\mathrm{g} \mathrm{L}^{-1}\right)$ & 0,28 & 0,23 & 0,77 & 0,52 \\
\hline
\end{tabular}

* Macronutrientes essenciais: Nitrogênio(N); fósforo $(\mathrm{P})$; potássio $(\mathrm{K})$; sódio $(\mathrm{Na})$; cálcio $(\mathrm{Ca})$ e $\mathrm{Magnésio}(\mathrm{Mg})$.

Fonte: Elaboração dos autores.

Os dados justificam novos estudos, em função de que a metodologia utilizada na coleta das amostras, provavelmente, interferiu nos resultados. Ao ser coado o material coletado, alguns pedaços de pescado ainda não estavam totalmente dissolvidos no tratamento com $33 \%$ de resíduo, em ambos os sistemas, o que eventualmente pode ter conduzido a conclusões equivocadas sobre os resultados. Esse aspecto possivelmente explica, para alguns nutrientes, os menores teores na concentração de 
$33 \%$ se comparada a $16 \%$ de resíduo de pescado.

O esperado seria níveis mais elevados de nutrientes quando utilizada uma proporção maior de resíduos $(33 \%)$

Em relação aos teores de nitrogênio observados nos compostos, se feita uma comparação com os teores desde mesmo nutriente em materiais comumente utilizados em adubações orgânicas (esterco bovino, esterço de aves, torta de mamona, entre outros), tem-se valores muito superiores aos desses materiais (CFSEMG, 1999; OLIVEIRA, 2001; CQFS, 2004; FIOREZE; CERETTA, 2006).

Se compararmos o material desenvolvido neste estudo, com materiais existentes no mercado, como por exemplo, o FISH MAIS ${ }^{\circledR}$, que é caracterizado por ser um composto à base de aminoácido de peixe, produzido a base de resíduos frescos, possuindo nutrientes e aminoácidos livres (BASE FERTIL, 2013), observa-se que este material comercial, apresenta apenas, $2 \%$ de $\mathrm{N}$, quantidade muito inferior ao encontrado neste estudo.

\section{Conclusões}

O processo de compostagem da casca de arroz revelou-se incompleto durante o período de realização do experimento.

O composto elaborado com resíduos de pescado e casca esgotada de acácia apresenta-se como uma boa fonte de nutrientes para as culturas, sendo indicado como adubo orgânico para sistemas de produção de base ecológica.

O fertilizante orgânico líquido, nas condições em que o experimento foi realizado, apresenta-se como uma viável fonte de nutrientes para sistemas produtivos de base ecológica. Entretanto, estudos complementares necessitam ser conduzidos, para melhor entendimento e qualificação de ambos os processos.

\section{Referências}

ARRUDA, L. F.; BORGHESI, R.; OETTERER. Use of fish waste as silage: a review. Brazilian Archives of Biology and Technologyjcr, Curitiba, v. 50, n. 5, p. 879886, 2007.

BASE FERTIL. Produto FISH MAIS. Fertilizante líquido a base de peixe. Cravinhos: Base Fértil, 2013. Disponível em: $\quad<$ http://www.basefertilagricola.com.br/prod_det. php?id=8>. Acesso em: 05 maio 2013.

CARNEY, W.; BREITENBECK, G.; SCHELLINGER, D. Composting: a disposal method for fish waste. LSU Ag Center Experiment Dispels Fish Smell. Louisiana: LSU AgCenter Research e Extension, 2000. Available at: $<$ http://www.agctr.lsu.edu>. Accessed at: 15 jul. 2009.

COMISSÃO DE FERTILIDADE DO SOLO DO ESTADO DE MINAS GERAIS - CFSEMG. Recomendações para o uso de corretivos e fertilizantes em Minas Gerais. 5. ed. Lavras, 1999. 359 p.

COMISSÃO DE QUÍMICA E FERTILIDADE DO SOLO - CQFS, RS/SC. Manual de adubação e calagem para os estados do Rio Grande do Sul e Santa Catarina. 10. ed. Porto Alegre, 2004. 394 p.

EMPRESA BRASILEIRA DE PESQUISA AGROPECUÁRIA - EMBRAPA. Centro Nacional de Pesquisa de Solos. Manual de métodos de análise de solo, Centro Nacional de Pesquisa de Solos. 2. ed. rev. atual. Rio de Janeiro: Embrapa, 1997. 212 p.

FERNANDES, F.; SOARES JUNIOR, M. S. Produção em escala industrial de fertilizantes orgânicos por compostagem dos resíduos gerados pela agroindústria. Semina: Ciências Agrárias, Londrina, v. 13, n. 1, p. 5156, 1992.

FIOREZE, C.; CERETTA, C. A. Fontes orgânicas de nutrientes em sistemas de produção de batata. Ciência Rural, Santa Maria, v. 36, n. 6, p. 1788-1793, 2006.

KIEHL, E. J. Manual de compostagem: maturação e qualidade do composto. Piracicaba: E. J. Kiehl, 1998. $173 \mathrm{p}$.

MINISTÉRIO DA AGRICULTURA, PECUÁRIA E ABASTECIMENTO - MAPA. Instrução Normativa $\mathrm{n}^{\circ}$ 64, do Ministério da Agricultura, Pecuária e Abastecimento. Instrução Normativa ${ }^{\circ} 64$. Brasília: DF, 18 dez. 2008.

OETTERER, M. Industrialização do pescado cultivado. Piracicaba: Ed. Agropecuária, 2002. 200 p.

$O$ processo de fermentação do pescado: anchovamento. 2006. Dissertação (Mestrado em Ciências e Tecnologias de Alimentos) - Universidade de São 
Paulo, Escola Superior de Agricultura Luiz de Queiróz, Piracicaba.

OLIVEIRA, A. P. Uso de esterco bovino e húmus de minhoca na produção de repolho híbrido. Horticultura Brasileira, Brasília, v. 19, n. 1, p. 70-73, 2001.

OLIVEIRA, F. N. S.; LIMA, H. J. M.; CAJAZEIRA, J. P. Uso da compostagem em sistemas agrícolas orgânicos. Francisco: Embrapa Agroindústria Tropical, 2004. 17 p. (Embrapa Agroindústria Tropical. Documentos, 89).

RAMBO, B. A fisionomia do Rio Grande do Sul. 3. ed. São Leopoldo: Editora da Universidade do Vale do Rio dos Sinos, 1994. 473 p.

RICHARD, T. Cornell cooperative extension. waste management institute. Tennessee: Agricultural Extension Service, 1995. Available at: <http://www.compost.css. cornell.edu/Factsheets/FS5.html $>$. Accessed at: 8 jul. 2011.

ROSA, M. J. S. Aproveitamento integral dos resíduos da filetagem de tilápia e avaliação do impacto econômico. 2009. Dissertação (Mestrado em Aquicultura) Universidade Estadual Paulista. Centro de Aqüicultura, Jaboticabal.
TATTERSON, I. N.; WINDSOR, M. L. Fish silage. Journal Science Food Agriculture, London, v. 25, n. 1, p. 369-379, 1974.

TEDESCO, M. J.; GIANELLO, C.; BISSANI, C. A.; BOHNEN, H.; VOLKWEISS, S. J. Análises de solo, plantas e outros materiais. Porto Alegre: UFRGS, 1995.

UCHIDA, E. M.; FERROLI, F.; GONÇALVES, L. U.; VIEGAS, E. M. M. Produção de silagem de peixe destinada à adubação orgânica. In: SIMPÓSIO INTERNACIONAL DE INICIAÇÃO CIENTÍFICA DA UNIVERSIDADE DE SÃO PAULO, 15., 2007, Pirassununga. Anais... Pirassununga: Departamento de Informática da Codage/USP, 2007.

VIDOTTI, R. M.; GONÇALVES, G. S. Produção e caracterização de silagem, farinha e óleo de Tilápia e sua utilização na alimentação animal. São Paulo: Instituto de Pesca, 2006. (Texto técnico). Disponível em: $<$ http://www.pesca.sp.gov.br>. Acesso em: 20 out. 2012. 
